\title{
Efficacy and safety of PEG-asparaginase versus E. coli L-asparaginase in Chinese children with acute lymphoblastic leukemia: a meta-analysis
}

\author{
Zhan-Jing Dai^, Yan-Qin Huang, Yun Lu \\ Center for Health Care Policy Research, School of International Pharmaceutical Business, China Pharmaceutical University, Nanjing, China \\ Contributions: (I) Conception and design: ZJ Dai, Y Lu; (II) Administrative support: Y Lu; (III) Provision of study materials or patients: ZJ Dai, YQ \\ Huang; (IV) Collection and assembly of data: ZJ Dai, YQ Huang; (V) Data analysis and interpretation: All authors; (VI) Manuscript writing: All \\ authors; (VII) Final approval of manuscript: All authors. \\ Correspondence to: Yun Lu. Center for Health Care Policy Research, School of International Pharmaceutical Business, China Pharmaceutical \\ University, 639 Longmian Avenue, Jiangning District, Nanjing, China. Email: luyun78@163.com.
}

Background: Multiagent chemotherapy is the primary treatment for acute lymphoblastic leukemia (ALL), of which asparaginases including Escherichia coli L-asparaginase (E. coli L-Asp) and pegylated-asparaginase (PEG-Asp), are cornerstone components. The study aimed to conduct a meta-analysis to compare the efficacy and safety of PEG-Asp with E. coli L-Asp in Chinese children with ALL.

Methods: A systematic literature search was conducted to collect randomized controlled trials (RCTs) on PEG-Asp versus E. coli L-Asp in Chinese children with ALL. Two reviewers independently selected articles and extracted data. Risk-of-bias assessment was conducted with Cochrane recommendation tool. Pooled estimates and risk ratios (RRs) with $95 \%$ confidence intervals (CIs) were calculated for all outcomes in Review Manager 5.3.

Results: Out of the 470 publications screened, 15 studies were included, involving 1,194 patients. Pooled estimates showed that there were no significant differences in complete responses (CR), overall response rate (ORR), gastrointestinal symptoms, and coagulation abnormalities rate between the PEG-Asp and E. coli L-Asp groups (all $\mathrm{P}>0.05$ ). Hypersensitivity ( $R R=0.63 ; 95 \% \mathrm{CI}, 0.40-1.01 ; \mathrm{P}=0.05$ ) and hepatic injury rate $(\mathrm{RR}=0.45 ; 95 \% \mathrm{CI}, 0.27-0.75 ; \mathrm{P}=0.002)$ were lower in the PEG-Asp group. The frequency of administration and length of hospital stay of patients in the PEG-Asp group were less than those in the E. coli L-Asp group (both $\mathrm{P}<0.0001)$.

Conclusions: Current evidence pointed out a similar efficacy in the two groups. The PEG-Asp group showed a lower hypersensitivity and hepatic injury rate. In addition, using PEG-Asp decreased the frequency of administration and the length of hospital stay, which, to some extent, might reduce patients' burden caused by medical resource consumption.

Keywords: Pegylated-asparaginase (PEG-Asp); Escherichia coli L-asparaginase (E. coli L-Asp); childhood acute lymphoblastic leukemia (childhood ALL); meta-analysis

Submitted Jul 07, 2020. Accepted for publication Dec 04, 2020.

doi: $10.21037 / \mathrm{tp}-20-178$

View this article at: http://dx.doi.org/10.21037/tp-20-178

\footnotetext{
^ ORCID: 0000-0003-1481-9562.
} 


\section{Introduction}

Acute lymphoblastic leukemia (ALL), characterized by the proliferation of immature lymphoid cells in bone marrow, peripheral blood, and other organs, is the most common subtype of leukemia in children and adolescents, representing $75 \%$ to $80 \%$ of acute leukemias among children (1). It accounts for $25 \%$ of all childhood cancers, which also makes it the most common pediatric malignancy of all childhood cancers (2). According to the literature published in 2019, the prevalence rate of leukemia in China was approximately 4/100,000 among people under 15 years of age (3).

The multiagent chemotherapy used in the treatment of children with ALL exhibits good efficacy, with a 5-year overall survival (OS) of $86-89 \%$ in children with ALL (1). Escherichia coli L-asparaginase (E. coli L-Asp), an enzyme that is the cornerstone in multiagent chemotherapy, has been established as an important part of regimens in ALL. However, the delivery of asparaginase can be highly immunogenic, as it is derived from bacteria (4-6). It may cause adverse events including hypersensitivity, thromboembolic events, and hepatotoxicity (7). Pegylated-asparaginase (PEG-Asp), an inert compound, is an enzyme conjugated to polyethylene glycol (PEG) molecules. In addition to the unaffected biological activity of asparaginase, PEGAsp greatly diminishes unappreciated immunogenicity (8). The half-life of PEG-Asp ( $7 \pm 2 \mathrm{~d})$ is significantly longer than that of E. coli L-Asp (20 h), indicating that PEG-Asp can reduce the frequency of administration (9).

PEG-Asp has been recommended as the first-line treatment by the Chinese guideline for the diagnosis and management of children with ALL (2018) and was admitted into the National Reimbursement Drug List (NRDL) through national drug price negotiation in 2018. The agreement is valid until the end of 2022. Whether PEGAsp will still be covered by NRDL in the future depends on the results of the following negotiations, while E. coli L-Asp has always been in the NRDL. In fact, no clear evidence has been published to prove that PEG-Asp and E. coli L-Asp have a significant difference in efficacy and safety (10-14). Additionally, there has been no meta-analysis targeting China's pediatric ALL patients. Therefore, the present study conducted a meta-analysis to compare the efficacy and safety of PEG-Asp and E. coli L-Asp in Chinese children with ALL, with the aim of providing supporting evidence for clinical medication and future negotiation of NRDL adjustment. We present the following article in accordance with the PRISMA reporting checklist (available at http:// dx.doi.org/10.21037/tp-20-178).

\section{Methods}

\section{Data sources and search strategy}

The meta-analysis was conducted according to the recommendations of the Cochrane Collaboration. We searched PubMed, Cochrane Library, China National Knowledge Infrastructure (CNKI), WanFang Data, and VIP Chinese periodical service platform, from inception to December 2019. Medical Subject Headings and text words included "polyethylene glycol conjugated asparaginase", "pegaspargase", "PEG-Asp", "Escherichia coli L-asparaginase", "E. coli L-Asp", "childhood acute lymphoblastic leukemia", and "ALL". References of the included studies were traced to dig out more relevant studies. The complete electronic search strategy for PubMed is provided in Appendix 1.

\section{Inclusion and exclusion criteria}

The PICO strategy recommended by Cochrane (15) was used to define the eligibility criteria. Randomized controlled trials (RCTs) that contained a control group and an intervention group and that fulfilled the following criteria were eligible for inclusion: (I) the study population consisted of Chinese patients aged $0-18$ years with ALL; (II) the experimental group (PEG-Asp group) was treated with multiagent chemotherapy composed of PEG-Asp, and E. coli L-Asp was used as the control group (E. coli L-Asp group). Other drugs involved in multiagent chemotherapy for the two groups were basically consistent, including vincristine or vindesine, daunorubicin or pirarubicin, and prednisone or prednisolone or dexamethasone; (III) efficacy outcomes included complete responses (CR) and overall response rate (ORR). Safety outcomes included hypersensitivity rate, hepatic injury rate, gastrointestinal symptoms, and coagulation abnormalities. According to NCCN Guidelines and the Chinese guideline for the diagnosis and management of children with ALL (2018), the hypersensitivity reactions manifest clinically as urticaria, bronchospasm, angioedema, or anaphylaxis. Hepatic injury manifest clinically as elevation in bilirubin, aspartate aminotransferase (AST) and alanine aminotransferase (ALT). Gastrointestinal symptoms include nausea, vomiting and abdominal pain. Coagulation abnormalities are characterized by a decrease 
in prothrombin time (PT), and fibrinogen and an increase in D-dimer and partial thromboplastin time (PTT). Each study should report at least one of those outcomes; (IV) published in full manuscript form; (V) published in Chinese or English.

Studies were excluded if they were (I) study populations with severe complications (such as pulmonary infection) or other diseases (such as diabetes) and (II) duplicate publications. Each abstract was reviewed by two examiners, and any manuscript deemed potentially relevant was retrieved in full text and screened independently, with discrepancies resolved through consensus.

\section{Data extraction and risk-of-bias assessment}

Two authors (ZJD and YQH) extracted data independently and resolved disagreements by discussion until reaching consensus. For each eligible study, the following information was extracted: (I) basic information (e.g., first author, year of publication, sample size); (II) intervention and study population baseline characteristics; and (III) efficacy and safety outcomes as mentioned in the inclusion criteria. The quality of the included studies was assessed by using the Cochrane risk-of-bias tool (15). Assessment domains include selection bias, performance bias, detection bias, attrition bias, reporting bias, and other biases. Publication bias assessment was conducted through visual inspection of a funnel plot and Egger's test which was performed in Stata/MP version 13.0 (StataCorp LLC., TX, USA) (16). If publication bias existed, the trim-and-fill approach was implemented to generate an estimated pooled RR that accounts for unpublished negative findings (17).

\section{Statistical analysis}

The meta-analysis was undertaken in Review Manager version 5.3 (Cochrane Collaboration, Copenhagen, Denmark). The risk ratio (RR) with $95 \%$ CI was used to evaluate dichotomous outcomes, and the mean difference (MD) with 95\% CI was generated to evaluate continuous outcomes. Heterogeneity was assessed by using the $\mathrm{I}^{2}$ estimate and the $\mathrm{P}$ value of the $\chi^{2}$-test. If the $\mathrm{P}$ value $>0.10$ and $\mathrm{I}^{2}<50 \%$, the assumption of homogeneity was made and the fixed-effects (FE) model was used for analyses. Otherwise, heterogeneity was assumed, and its source should be further determined by subgroup analysis or sensitivity analysis. Subgroup analyses were performed based on the treatment dosage of the E. coli L-Asp group.
Sensitivity analyses were undertaken with an exclusion of extreme dosage, any single study and studies without random sequence generation. In the absence of clear clinical and methodological heterogeneity, the random-effects (RE) model was used to analyze the outcomes.

\section{Results}

\section{Included studies}

Our search identified 470 publications through database searching. After screening titles and abstracts, 32 studies were considered potentially eligible and were retrieved for full-text review. Fifteen studies (18-32) were finally included in this meta-analysis. All included studies were in Chinese. The search procedure and reasons for exclusion can be found in the flowchart (Figure 1).

\section{Study characteristics}

The characteristics of the included studies are summarized in Table 1. There were a total of 1,194 patients, of which 594 were treated with PEG-Asp and 600 were treated with E. coli L-Asp.

\section{Risk-of-bias assessment}

Three $(26,28,30)$ of fifteen studies exhibited a high risk of bias in one domain, "random sequence generation". The methods taken to generate random sequences and arrange groups in these three studies did not accord with the randomization standard. Six $(18-20,22,25,32)$ studies described methods of randomization in detail. Only one study (19) illustrated allocation concealment. Blinding was not mentioned in any of the studies. One study (24) did not completely report the prespecified outcomes and was judged as high risk. No subjects withdrew from the studies. The domain "other bias" exhibited an unclear risk of bias due to insufficiency information. Details are shown in Figure 2.

\section{Meta-analysis results}

After summarizing the characteristics of the included studies, we found that the dosage of the PEG-Asp group was similar while there were some differences existing in that of the E. coli L-Asp group. Therefore, we conducted a subgroup analysis based on the dosage of the E. coli L-Asp group reported in the included studies. Subgroups were divided into (I) E. coli L-Asp: $\leq 6,000 \mathrm{U} / \mathrm{m}^{2}$ once, $6-10$ times, (II) 


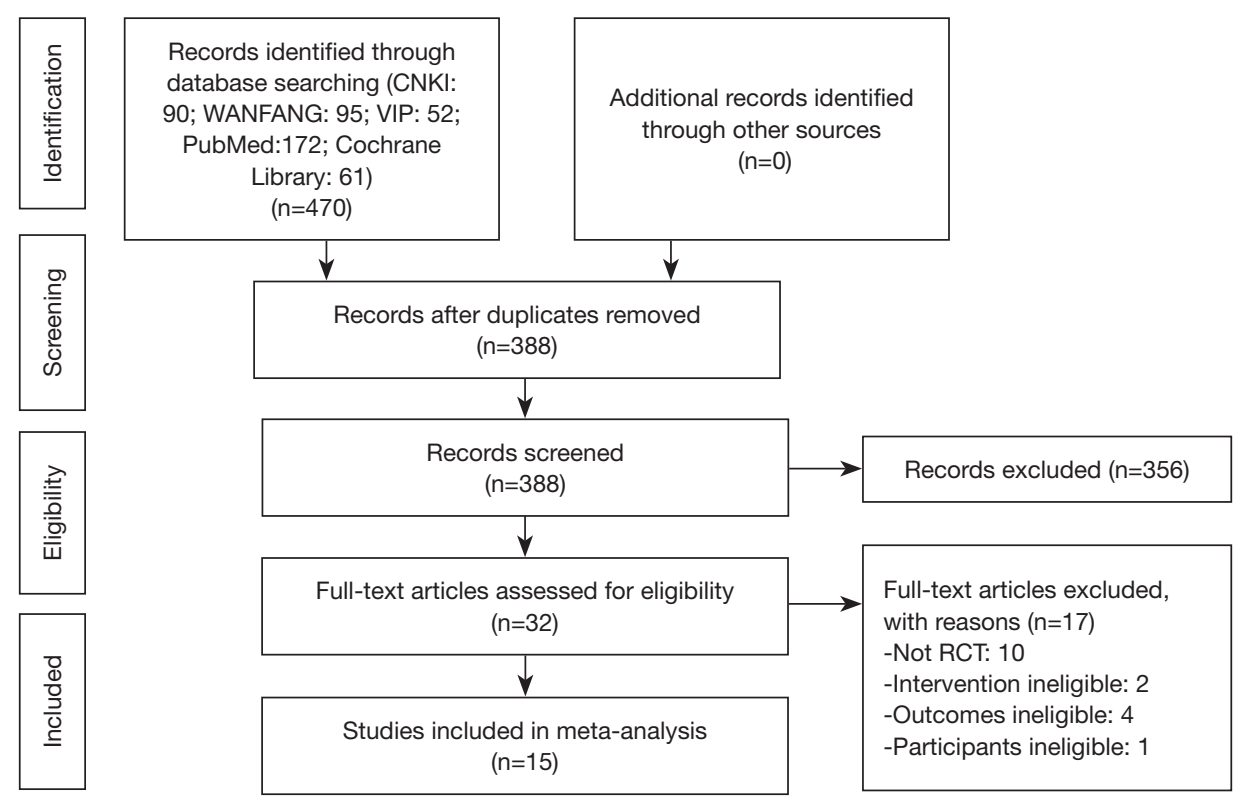

Figure 1 Flowchart of the study selection. RCT, randomized controlled trial.

E. coli L-Asp: 6,000-10,000 U/m² once, 6-10 times, (III) E. coli L-Asp: $700 \mathrm{U} / \mathrm{m}^{2}$ once, 7 times, and (IV) E. coli L-Asp: $200 \mathrm{U} / \mathrm{kg}$ once, 8 times.

\section{CR}

All fifteen studies which included 1,194 patients reported CR. The pooled analysis demonstrated that there was no significant difference in CR under the FE model between the PEG-Asp group and the E. coli L-Asp group (RR =1.01; 95\% CI, 0.96-1.08; P=0.64; Figure 3). No heterogeneity between studies was noted in each subgroup $\left(\mathrm{I}^{2}=0 \%, \mathrm{P}=0.86\right.$ in the subgroup with $E$. coli $\mathrm{L}$-Asp: $\leq 6,000 \mathrm{U} / \mathrm{m}^{2}$ once, 6-10 times; and $\mathrm{I}^{2}=26 \%, \mathrm{P}=0.25$ in the subgroup with $E$. coli L-Asp: 6,000-10,000 $\mathrm{U} / \mathrm{m}^{2}$ once, 6-10 times).

\section{ORR}

Thirteen studies including 1,099 patients reported ORR. Homogeneity was assumed as a $\mathrm{P}$ value $>0.10$ and $\mathrm{I}^{2}<50 \%$ in each subgroup and the pooled estimates. The FE model was applied and pooled estimates showed that there was no significant difference in ORR between the PEG-Asp group and the E. coli L-Asp group ( $\mathrm{RR}=1.03 ; 95 \%$ CI, 1.00-1.06; $\mathrm{P}=0.06$; Figure 4).

\section{Adverse events}

Eight studies (715 patients) reported the hypersensitivity rate and four studies (239 patients) reported the hepatic injury rate. Homogeneity was assumed as the $\mathrm{I}^{2}$ was $0 \%$. The FE model was applied, and the results showed that there was a lower hepatic injury rate $(\mathrm{RR}=0.45 ; 95 \% \mathrm{CI}$, $0.27-0.75 ; \mathrm{P}=0.002)$ and a lower hypersensitivity rate $(\mathrm{RR}$ $=0.63,95 \% \mathrm{CI}, 0.40-1.01 ; \mathrm{P}=0.05)$ in the PEG-Asp group than in the E. coli L-Asp group. In terms of gastrointestinal symptoms and coagulation abnormalities reported by ten and nine studies respectively, the PEG-Asp group and the E. coli L-Asp group did not show obvious dissimilarity $(\mathrm{P}>0.05)$. Details are described in Figure 5 .

\section{Frequency of administration and length of hospital stay} In addition to the efficacy and adverse events, we considered some other relevant resources used during the treatment, such as the administration and hospital stay. Five included studies (407 patients) reported the frequency of administration and the length of hospital stay. The analysis was conducted under the $\mathrm{FE}$ model as $\mathrm{I}^{2}$ was $0 \%$. The frequency of administration and length of hospital stay of patients in the PEG-Asp groups were both significantly less than those of patients in the E. coli L-Asp groups (MD $=-5.58,95 \% \mathrm{CI},-5.92$ to $-5.24 ; \mathrm{MD}=-7.04,95 \% \mathrm{CI},-8.06$ to -6.02 ; both $\mathrm{P}<0.00001$; Figure 6).

\section{Sensitivity analysis results}

With the exclusion of any single study, the heterogeneity 
Table 1 Characteristics of included studies

\begin{tabular}{|c|c|c|c|c|c|}
\hline Author, year & $\begin{array}{l}\text { Sample size, } \\
\text { E/C (\%/male })\end{array}$ & $\begin{array}{l}\text { Mean age, } \\
\text { E/C (years) }\end{array}$ & \multicolumn{2}{|l|}{ Intervention } & Outcomes \\
\hline Cheng X, 2015 & $\begin{array}{l}74(54.05 \%) \\
/ 74(62.16 \%)\end{array}$ & $\begin{array}{l}14.09 \pm 1.25 \\
/ 13.28 \pm 1.17\end{array}$ & $\begin{array}{c}\mathrm{IM}, 2,500 \mathrm{U} / \mathrm{m}^{2} \text { once, once } / 14 \mathrm{~d}, \\
\text { twice }\end{array}$ & $\begin{array}{l}\mathrm{IV}, 6,000 \mathrm{U} / \mathrm{m}^{2} \text { once, } \\
\text { once/2 } \mathrm{d}, 8 \text { times }\end{array}$ & (a) (b) (c) (e) (f) \\
\hline $\begin{array}{l}\text { Cooperation } \\
\text { group, } 2008\end{array}$ & $\begin{array}{l}65(63.08 \%) \\
/ 66(65.15 \%)\end{array}$ & $9.0 \pm 5.0 / 8.0 \pm 4.4$ & $\begin{array}{c}\mathrm{IM}, 2,500 \mathrm{U} / \mathrm{m}^{2} \text { once, } \\
\text { administered on days } 10 \text { and } 24\end{array}$ & $\begin{array}{l}\mathrm{IV}, 6,000 \mathrm{U} / \mathrm{m}^{2} \text { once, } \\
\text { once/2 } \mathrm{d}, 8 \text { times }\end{array}$ & (a) (b) (c) \\
\hline Jin H, 2014 & $40 / 30$ & - & $\begin{array}{c}\mathrm{IM}, \mathrm{BSA}>0.6 \mathrm{~m}^{2}, 2,500 \mathrm{U} / \mathrm{m}^{2} \\
\text { once, } \mathrm{BSA} \leq 0.6 \mathrm{~m}^{2}, 82.5 \mathrm{U} / \mathrm{kg} \\
\text { once, once } / 14 \mathrm{~d}\end{array}$ & $\begin{array}{l}\text { IV, } 700 \mathrm{U} / \mathrm{m}^{2} \text { once, } \\
\text { once/ } 2 \mathrm{~d}, 7 \text { times }\end{array}$ & (a) (b) (c) (e) (f) (g) (h) \\
\hline Li F et al., 2019 & $\begin{array}{l}45(57.78 \%) \\
/ 44(54.55 \%)\end{array}$ & $5.7 \pm 1.5 / 6.1 \pm 1.8$ & $\mathrm{IM}, 2,500 \mathrm{U} / \mathrm{m}^{2}$ once, once/14 d & $\begin{array}{l}\text { IV, } 200 \mathrm{U} / \mathrm{kg} \text { once, } \\
\text { once/2 d, } 8 \text { times }\end{array}$ & (a) (b) (c) (e) (f) (h) \\
\hline Liu Z, 2019 & $\begin{array}{l}38(57.89 \%) \\
/ 38(63.16 \%)\end{array}$ & $6.4 \pm 1.2 / 6.3 \pm 1.0$ & $\begin{array}{c}\mathrm{IM}, \mathrm{BSA}>0.6 \mathrm{~m}^{2}, 2,500 \mathrm{U} / \mathrm{m}^{2} \\
\text { once, } \mathrm{BSA} \leq 0.6 \mathrm{~m}^{2}, 82.5 \mathrm{U} / \mathrm{kg} \\
\text { once, once } / 14 \mathrm{~d}\end{array}$ & $\begin{array}{l}\mathrm{IV}, 6,000-10,000 \mathrm{U} / \mathrm{m}^{2} \\
\text { once, once/2 d, } \\
6-10 \text { times }\end{array}$ & (a) (b) (d) (e) \\
\hline Shi L et al., 2019 & $\begin{array}{l}37(57.46 \%) \\
/ 37(56.76 \%)\end{array}$ & $4.5 \pm 1.1 / 4.7 \pm 1.2$ & $\begin{array}{c}\mathrm{IM}, \mathrm{BSA}>0.6 \mathrm{~m}^{2}, 2,500 \mathrm{U} / \mathrm{m}^{2} \\
\text { once, } \mathrm{BSA} \leq 0.6 \mathrm{~m}^{2}, 82.5 \mathrm{U} / \mathrm{kg} \\
\text { once, once } / 14 \mathrm{~d}\end{array}$ & $\begin{array}{l}\text { IV, 6,000 U/m } \mathrm{m}^{2} \text { once, } \\
\text { once/2 d, 6-10 times }\end{array}$ & (a) (b) (d) (e) (f) \\
\hline Tang Y et al., 2016 & $\begin{array}{l}31(67.74 \%) \\
/ 31(64.52 \%)\end{array}$ & $7.8 \pm 3.4 / 7.6 \pm 3.3$ & $\begin{array}{l}\mathrm{IM}, 2,500 \mathrm{U} / \mathrm{m}^{2} \text { once, } \\
\text { once/month }\end{array}$ & $\begin{array}{l}\text { IV, } 10,000 \mathrm{U} / \mathrm{m}^{2} \text { once, } \\
3 \text { times/week }\end{array}$ & (a) (b) (c) (e) (f) (g) (h) \\
\hline Wu H, 2016 & $\begin{array}{l}35(57.14 \%) \\
/ 35(51.43 \%)\end{array}$ & $5.4 \pm 1.2 / 5.7 \pm 1.0$ & $\begin{array}{c}\mathrm{IM}, 2,500 \mathrm{U} / \mathrm{m}^{2} \text { once, once } / 14 \mathrm{~d}, \\
\text { twice }\end{array}$ & $\begin{array}{l}\mathrm{IV}, 6,000 \mathrm{U} / \mathrm{m}^{2} \text { once, } \\
\text { once/2 } \mathrm{d}, 8 \text { times }\end{array}$ & (a) (b) (c) (e) (f) (g) (h) \\
\hline $\begin{array}{l}\text { Zhang H et al., } \\
2017\end{array}$ & $\begin{array}{l}27(40.74 \%) \\
/ 27(44.44 \%)\end{array}$ & $6.9 \pm 2.0 / 6.8 \pm 2.1$ & $\begin{array}{l}\mathrm{IM}, \mathrm{BSA}>0.6 \mathrm{~m}^{2}, 2,500 \mathrm{U} / \mathrm{m}^{2} \\
\text { once, once } / 14 \mathrm{~d} \text {, twice }\end{array}$ & $\begin{array}{l}\mathrm{IV}, 6,000-10,000 \mathrm{U} / \mathrm{m}^{2} \\
\text { once, once/2d, } \\
6-10 \text { times }\end{array}$ & (a) (b) (d) (g) (h) \\
\hline Zhang S, 2015 & $\begin{array}{l}30(56.67 \%) \\
/ 30(46.67 \%)\end{array}$ & $5.8 \pm 1.1 / 6.1 \pm 1.4$ & $\begin{array}{c}\mathrm{IM}, 2,500 \mathrm{U} / \mathrm{m}^{2} \text { once, once } / 14 \mathrm{~d}, \\
\text { twice }\end{array}$ & $\begin{array}{l}\mathrm{IV}, 6,000 \mathrm{U} / \mathrm{m}^{2} \text { once, } \\
\text { once/2 } \mathrm{d}, 8 \text { times }\end{array}$ & (a) \\
\hline $\begin{array}{l}\text { Zhang S et al., } \\
2015\end{array}$ & $48 / 47$ & - & $\begin{array}{c}\mathrm{IM}, 2,500 \mathrm{U} / \mathrm{m}^{2} \text { once, once } / 14 \mathrm{~d} \text {, } \\
\text { twice }\end{array}$ & $\begin{array}{l}\mathrm{IV}, 10,000 \mathrm{U} / \mathrm{m}^{2} \text { once, } \\
\text { once/week, } 6 \text { times }\end{array}$ & (a) (b) (e) (f) (g) (h) \\
\hline
\end{tabular}

(a): CR; (b): ORR; (c): hypersensitivity; (d): hepatic injury; (e): gastrointestinal symptoms; (f): coagulation abnormalities; (g): frequency of administration; (h): length of hospital stay. E, experimental group; C, control group; d, day; -, not reported; IM, delivered intramuscularly; IV, delivered intravenously; BSA, body surface area; CR, complete responses; ORR, overall response rate; PEG-Asp, pegylatedasparaginase; E. coli L-Asp, Escherichia coli L-asparaginase. 


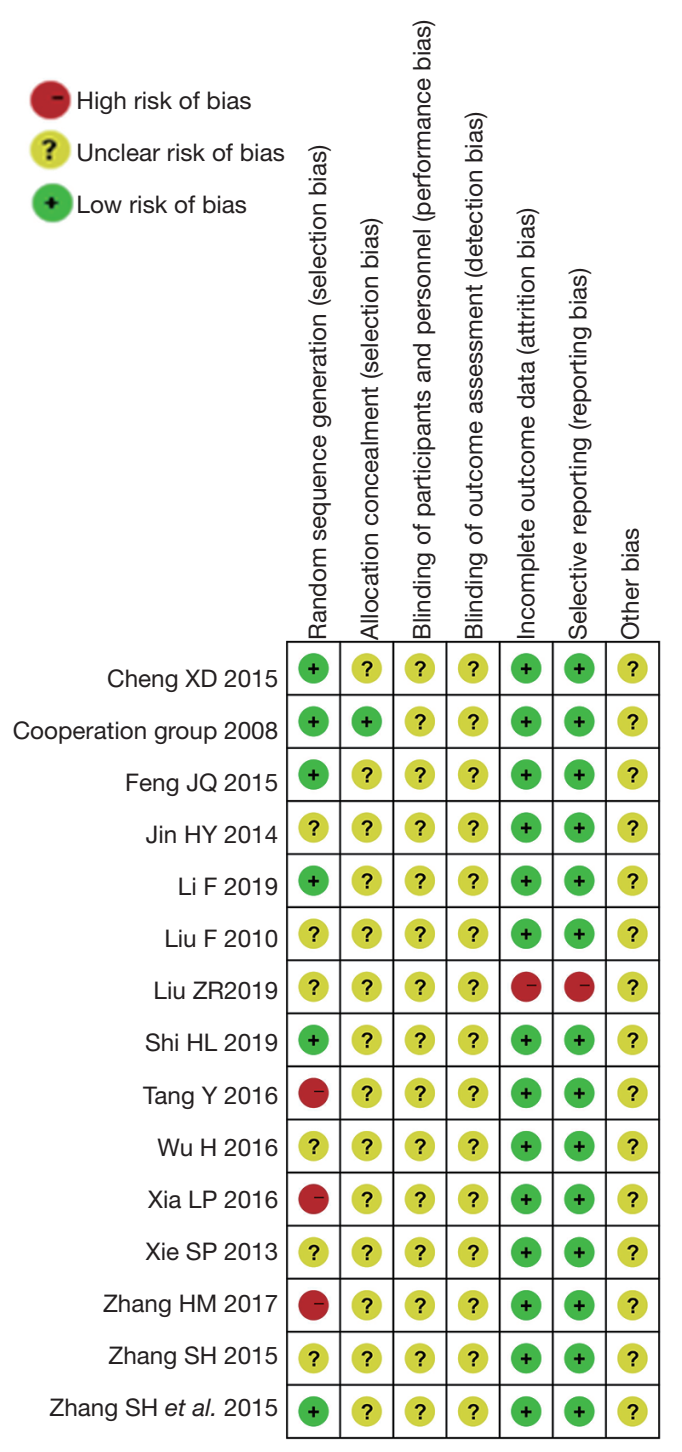

Figure 2 Risk-of-bias summary of authors' judgments about each risk-of-bias item for each included study.

did not change materially in terms of any efficacy outcomes, safety outcomes, frequency of administration, and length of hospital stay.

After two extreme dosage subgroups were excluded (E. coli L-Asp: $700 \mathrm{U} / \mathrm{m}^{2}$ once, 7 times, and E. coli L-Asp: $200 \mathrm{U} / \mathrm{kg}$ once, 8 times), the pooled estimate results of CR and ORR did not change $(\mathrm{RR}=1.01,95 \% \mathrm{CI}, 0.95-1.07$, $\mathrm{P}=0.81 ; \mathrm{RR}=1.02,95 \% \mathrm{CI}, 0.99-1.06, \mathrm{P}=0.17$, respectively).

Ruling out the three studies (Tang Y et al. 2016, Xia L 2016 and Zhang $\mathrm{H}$ et al. 2017) without random sequence generation did not have a great influence on the pooled estimate results of CR and ORR (RR $=0.99,95 \% \mathrm{CI}$,
0.93-1.05, $\mathrm{P}=0.79 ; \mathrm{RR}=1.02,95 \% \mathrm{CI}, 0.99-1.05, \mathrm{P}=0.19$, respectively). In terms of hepatic injury rate, the pooled estimate result changed, showing no difference between the PEG-Asp group and the E. coli L-Asp group (RR $=0.79,95 \% \mathrm{CI}, 0.48-1.30, \mathrm{P}=0.36$ ), after excluding the two studies (Tang Y et al. 2016 and Xia L 2016) without random sequence generation. There was no significant change in other safety outcomes. For the frequency of administration and length of hospital stay, the exclusion of the study (Tang $Y$ et al. 2016) without random sequence generation did not materially change the substantial heterogeneity and pooled estimate results.

\section{Publication bias}

The asymmetry displayed in the funnel plots indicated some publication bias (Figure 7). The $\mathrm{P}$ value of 0.031 (95\% CI, 0.82-1.44) was calculated by Egger's test based on the CR, which also suggested the presence of publication bias. The trim and fill approach was applied to generate an adjusted estimated pooled fixed effects RR of 0.99 (95\% CI, 0.95-1.03), and four studies were filled. Compared with the initial RR of 1.01 (95\% CI, 0.96-1.08), the adjusted RR changed mildly. This result indicated that the original result was robust despite some publication bias. For ORR, the $\mathrm{P}$ value was calculated as 0.125 (95\% CI, -0.28 to 2.00), indicating no presence of publication bias. Funnel plots and Egger's test were not evaluated for AEs, frequency of administration and length of hospital stay due to the relatively small number of studies (15).

\section{Discussion}

This meta-analysis focused on the efficacy and safety of PEG-asparaginase versus E. coli L-Asp in Chinese children with ALL, involving a total of fifteen studies and 1,194 patients. Patients in the PEG-Asp group often received a similar dosage, two doses of $2,500 \mathrm{U} / \mathrm{m}^{2} \mathrm{PEG}-$ Asp. As apparent differences existed in the dosage of the E. coli L-Asp group, a subgroup analysis was conducted according to the dosage difference. The results showed that there was no obvious dissimilarity in subgroups concerning CR and ORR. It seemed that the difference in E. coli L-Asp dosage would not have an impact on the pooled result. Furthermore, we removed the two extreme dosage subgroups (E. coli L-Asp: $700 \mathrm{U} / \mathrm{m}^{2}$ once, 7 times, and E. coli L-Asp: $200 \mathrm{U} / \mathrm{kg}$ once, 8 times) to perform the sensitivity analysis, and the pooled estimate results did not change 


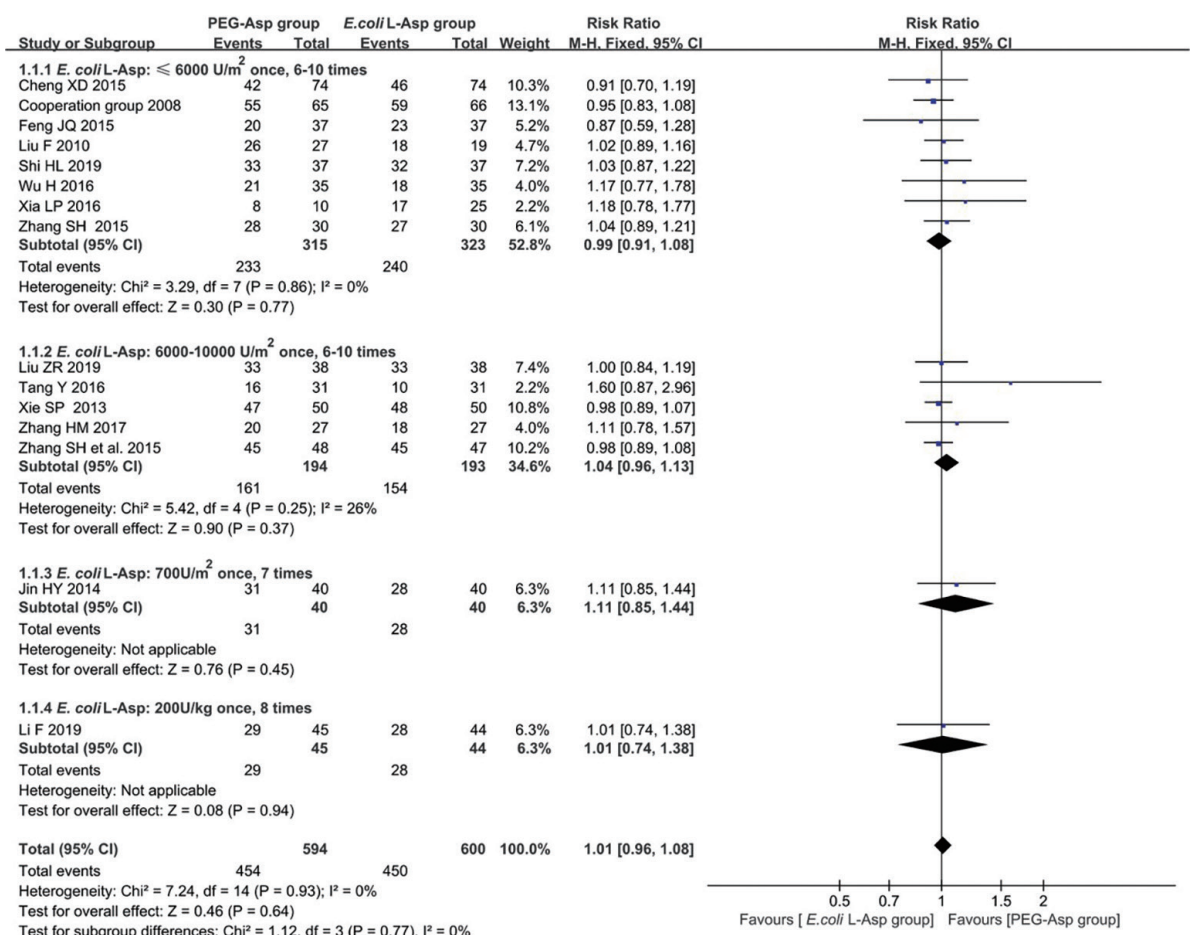

Figure 3 Forest plot of CR for the PEG-Asp group versus the E. coli L-Asp group. CR, complete responses; PEG-Asp, pegylated-asparaginase; E. coli L-Asp, Escherichia coli L-asparaginase; ALL, acute lymphoblastic leukemia; M-H, Mantel-Haenszel; CI, confidence interval.

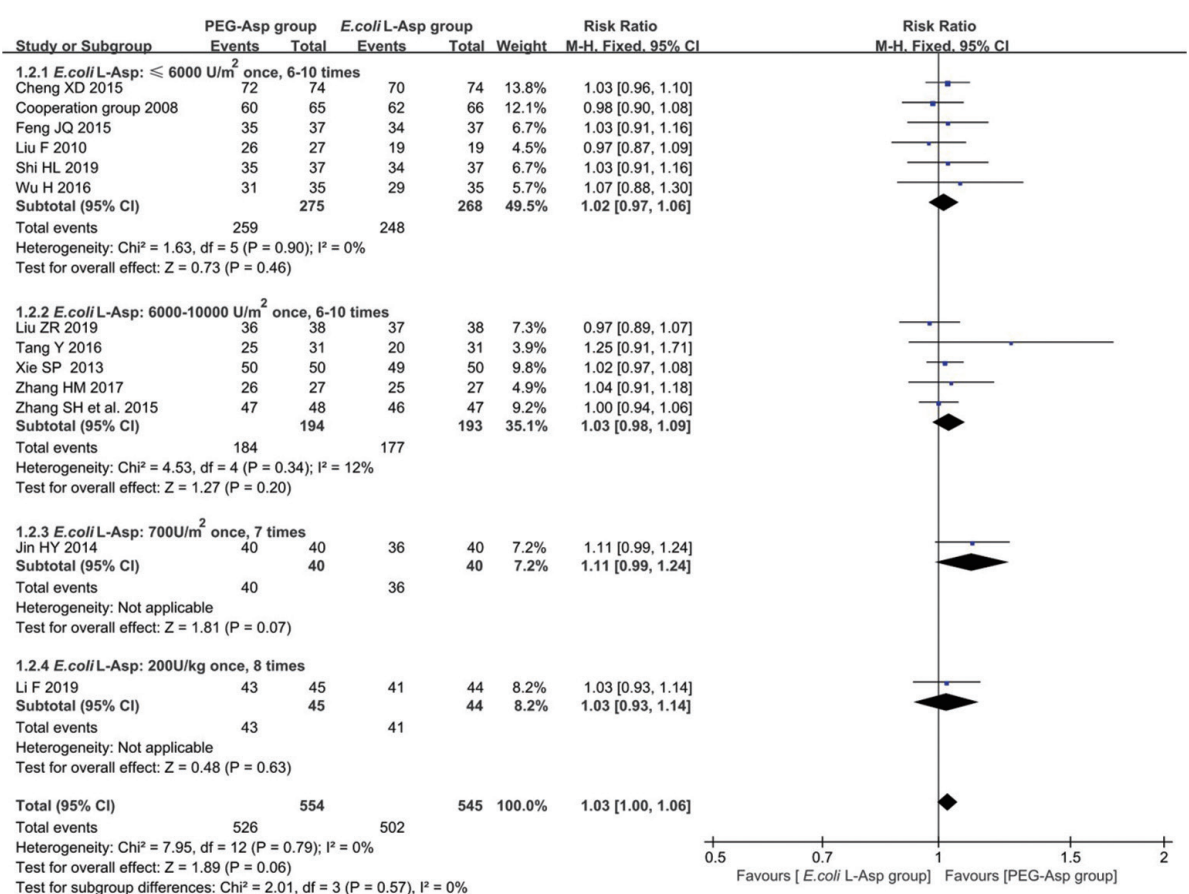

Figure 4 Forest plot of ORR for the PEG-Asp group versus the E. coli L-Asp group. ORR, overall response rate; PEG-Asp, pegylatedasparaginase; E. coli L-Asp, Escherichia coli L-asparaginase; ALL, acute lymphoblastic leukemia; M-H, Mantel-Haenszel; CI, confidence interval. 


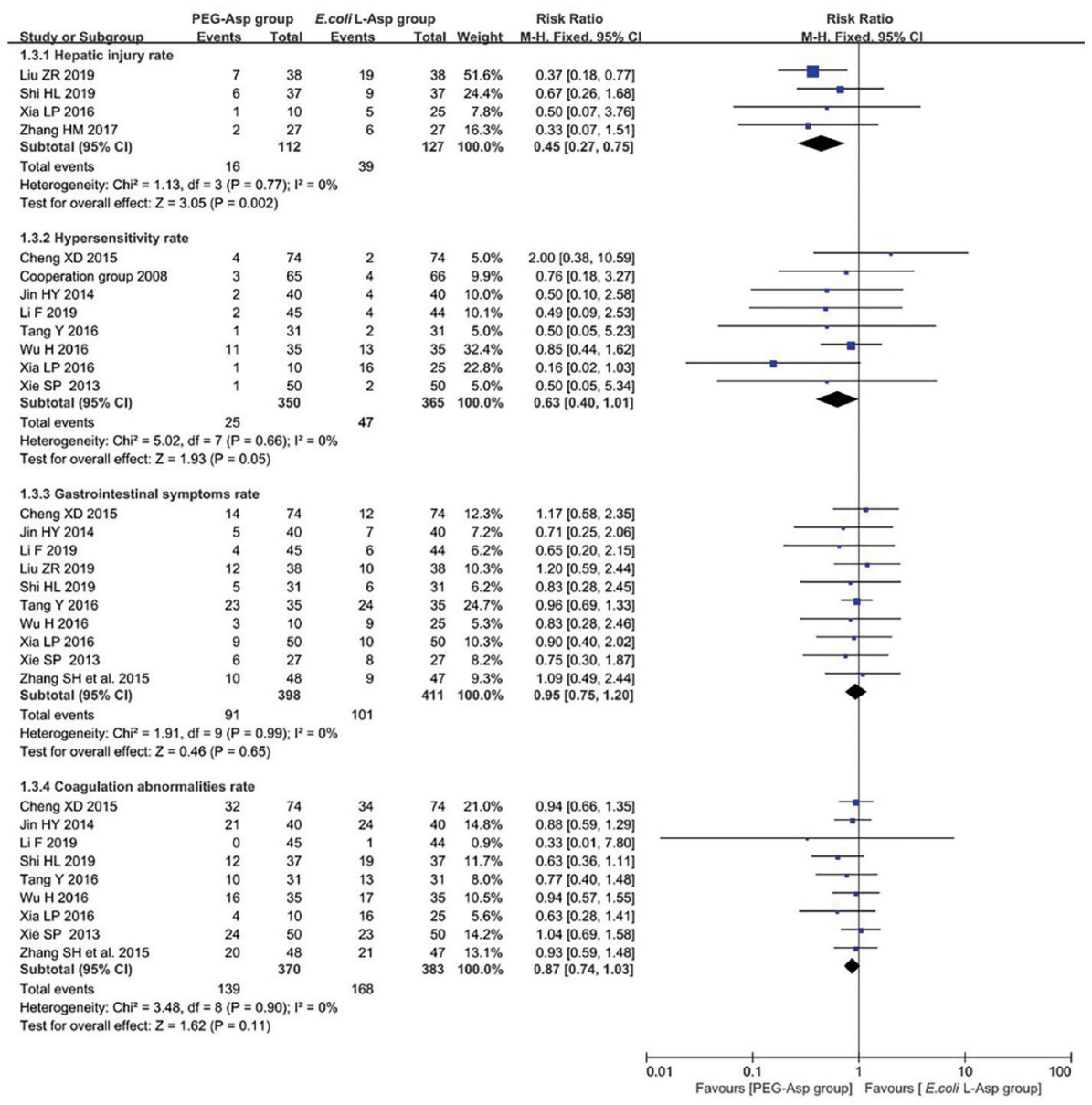

Figure 5 Forest plot of adverse events for the PEG-Asp group versus the E. coli L-Asp group. PEG-Asp, pegylated-asparaginase; E. coli L-Asp, Escherichia coli L-asparaginase; M-H, Mantel-Haenszel; CI, confidence interval.

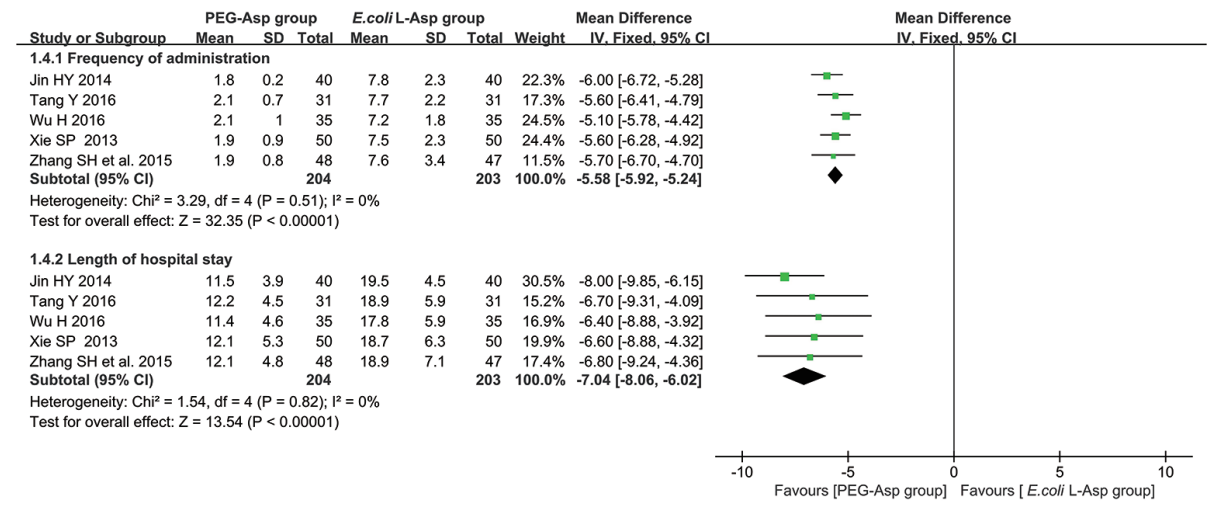

Figure 6 Forest plot of frequency of administration and length of hospital stay for the PEG-Asp group versus the E. coli L-Asp group. PEGAsp, pegylated-asparaginase; E. coli L-Asp, Escherichia coli L-asparaginase; IV, inverse variance; CI, confidence interval. 

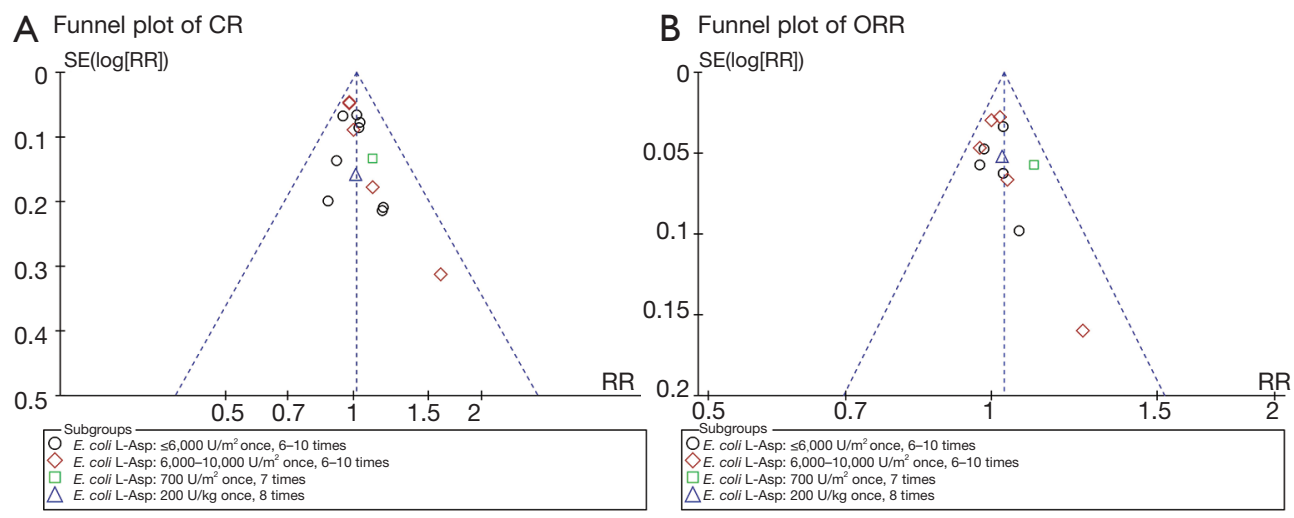

Figure 7 Funnel plots of CR (A) and ORR (B). CR, complete responses; ORR, overall response rate.

significantly.

In our study, quantitative analysis was not performed on long-term efficacy, because only one included study (23) provided the predicted progression-free survival (PFS) and OS by using Kaplan-Meier analysis. They predicted a 5 -year PFS of $63.5 \% \pm 12.5 \%$ for the PEG-Asp group and $77.8 \% \pm 9.8 \%$ for the E. coli L-Asp group; a 5 -year OS of $68.9 \% \pm 11.8 \%$ for the PEG-Asp group and $82.1 \% \pm 9.5 \%$ for the E. coli L-Asp group. The difference in PFS and OS was not significant between groups. This is consistent with the systematic evaluation result of Medawar (33), which was based on populations of the USA, Puerto Rico, and Canada. Studies from the United States and India conducted evaluations on local patients and also demonstrated that there were no significant differences between the two groups in terms of event-free survival and OS (11-13).

Regarding safety, our meta-analysis showed that the PEG-Asp group had a lower hypersensitivity rate and hepatic injury rate, without significant differences in the gastrointestinal symptoms rate and coagulation abnormalities rate. It is noteworthy in this metaanalysis that all included studies administered PEGAsp intramuscularly, which is the recommended method of administration in the Chinese guideline for the diagnosis and management of children with ALL (2018). However, due to patients' anxiety and pain, intravenous delivery is also practicable. One meta-analysis reported that the hypersensitivity rate between intramuscular and intravenous administration was not statistically significant (34). In addition, our results showed that both the frequency of administration and length of hospital stay of patients in the PEG-Asp group were significantly less than those of patients in the E. coli L-Asp group, which indicated that using PEG-Asp could reduce the economic burden caused by administration and hospital stay.

In total, this study examined 1,194 patients, which improved the statistical power and precision. However, there are several limitations of this meta-analysis. First, all the included studies were published in Chinese, and the study populations were all small. The results of Egger's test and the trim-and-fill approach indicated the presence of publication bias. Second, the result of the risk-of-bias assessment presented a large proportion of uncertain risks for insufficient information in methods of the trial. Third, our study lacked an analysis of long-term outcomes. Only one included study (23) provided long-term outcomes, which makes the rendering quantitative synthesis impossible. Thus, more studies relevant to the long-term outcomes of PEG-Asp in the treatment of Chinese children with ALL are needed in the future to confirm the long-term efficacy and safety of PEG-Asp.

\section{Conclusions}

To summarize, current evidence shows that the use of PEGAsp as a core component in multiagent chemotherapy was not superior to E. coli $\mathrm{L}$-Asp in terms of efficacy in the treatment of Chinese children with ALL. More trials with adequate methods and longer follow-up are necessary to clarify their efficacy. However, the assessment of collected data showed that patients in the PEG-Asp groups had a lower hypersensitivity rate and hepatic injury rate. The use of PEG-Asp reduced the frequency of administration and shortened the length of hospital stay, which indicates that using PEG-Asp in pharmacotherapy could reduce the economic burden caused by using medical resources. 
Therefore, based on the conclusion of this meta-analysis, we recommend the use of PEG-Asp, and expect a period extension of PEG-Asp in the NRDL through the next national drug price negotiation.

Although there were some limitations of this study that we discussed earlier, this study complements special evidence in the Chinese population by conducting a metaanalysis to analyze the efficacy and safety of PEG-Asp in the treatment of Chinese children with ALL. The results are more representative of the response to PEG-Asp and E. coli L-Asp in the Chinese population. This study reduces the possibility of experts being misled by differences among individual RCTs, and generates new evidence in support of clinical medication and future negotiation of the NRDL adjustment.

\section{Acknowledgments}

Funding: The study was supported by the National Natural Science Foundation of China (Grant no. 71673298).

\section{Footnote}

Reporting Checklist: The authors have completed the PRISMA reporting checklist. Available at http://dx.doi. org/10.21037/tp-20-178

Peer Review File: Available at http://dx.doi.org/10.21037/tp20-178

Conflicts of Interest: All authors have completed the ICMJE uniform disclosure form (available at http://dx.doi. org/10.21037/tp-20-178). The authors have no conflicts of interest to declare.

Ethical Statement: The authors are accountable for all aspects of the work in ensuring that questions related to the accuracy or integrity of any part of the work are appropriately investigated and resolved.

Open Access Statement: This is an Open Access article distributed in accordance with the Creative Commons Attribution-NonCommercial-NoDerivs 4.0 International License (CC BY-NC-ND 4.0), which permits the noncommercial replication and distribution of the article with the strict proviso that no changes or edits are made and the original work is properly cited (including links to both the formal publication through the relevant DOI and the license).
See: https://creativecommons.org/licenses/by-nc-nd/4.0/.

\section{References}

1. National Comprehensive Cancer Network. NCCN Clinical Practice Guidelines in Oncology (NCCN Guidelines): pediatric acute lymphoblastic leukemia (version 2.2020). Available online: https://www.nccn.org/ professionals/physician_gls/pdf/ped_all.pdf (Accessed 20 May 2020).

2. Bhojwani D, Yang JJ, Pui CH. Biology of childhood acute lymphoblastic leukemia. Pediatr Clin North Am 2015;62:47-60.

3. Gong A, Di Y, Wang X, et al. Epidemiological data analysis of childhood acute lymphoblastic leukemia. Chinese Medical Record 2019;20:59-62.

4. Kako S, Akahoshi Y, Harada N, et al. Meta-analysis and meta-regression analysis to compare the outcomes of chemotherapy for T- and B-lineage acute lymphoblastic leukemia (ALL): the use of dexamethasone, L-asparaginase, and/or methotrexate may improve the outcome of T-lineage ALL. Ann Hematol 2016;95:87-92.

5. Peterson RG, Handschumacher RE, Mitchell MS. Immunological responses to L-asparaginase. J Clin Invest 1971;50:1080-90.

6. Raetz EA, Salzer WL. Tolerability and efficacy of L-asparaginase therapy in pediatric patients with acute lymphoblastic leukemia. J Pediatr Hematol Oncol 2010;32:554-63.

7. Kurre HA, Ettinger AG, Veenstra DL, et al. A pharmacoeconomic analysis of pegaspargase versus native Escherichia coli L-asparaginase for the treatment of children with standard-risk, acute lymphoblastic leukemia: the Children's Cancer Group study (CCG-1962). J Pediatr Hematol Oncol 2002;24:175-81.

8. Sun X, Xu Q, Ao G, et al. Antitumor agents: multidrug resistance and enhanced permeability and retention. Chinese Journal of New Drugs 2007;(1):16-20.

9. Hao Q, He Z. Safety of E. coli L-Asp and Peg-asp in Treatment of Children with Newly Diagnosed Acute Lymphoblastic Leukemia. Genomics and Applied Biology 2018;37:5006-11.

10. Avramis VI, Sencer S, Periclou AP, et al. A randomized comparison of native Escherichia coli asparaginase and polyethylene glycol conjugated asparaginase for treatment of children with newly diagnosed standard-risk acute lymphoblastic leukemia: a Children's Cancer Group study. Blood 2002;99:1986-94. 
11. Place AE, Stevenson KE, Vrooman LM, et al. Intravenous pegylated asparaginase versus intramuscular native Escherichia coli L-asparaginase in newly diagnosed childhood acute lymphoblastic leukaemia (DFCI 05-001): a randomised, open-label phase 3 trial. Lancet Oncol 2015;16:1677-90.

12. Kurtzberg J, Asselin B, Bernstein M, et al. Polyethylene Glycol-conjugated L-asparaginase versus native L-asparaginase in combination with standard agents for children with acute lymphoblastic leukemia in second bone marrow relapse: a Children's Oncology Group Study (POG 8866). J Pediatr Hematol Oncol 2011;33:610.

13. Vyas C, Jain S, Kapoor G, et al. Experience with generic pegylated L-asparaginase in children with acute lymphoblastic leukemia and monitoring of serum asparaginase activity. Pediatr Hematol Oncol 2018;35:331-40.

14. Liang Y. A randomized controlled study of pegaspargase and E. coli L-Asparaginase in the treatment of children with acute lymphoblastic leukemia. Practical Clinical Journal of Integrated Traditional Chinese and Western Medicine 2017;17:117-9.

15. Higgins JPT, Thomas J, Chandler J, et al. Cochrane Handbook for Systematic Reviews of Interventions version 6.1 (updated September 2020). Cochrane, 2020. Available online: https://www.training.cochrane.org/handbook (Accessed: May 2020).

16. Sedgwick $\mathrm{P}$, Marston L. How to read a funnel plot in a meta-analysis. BMJ 2015;351:h4718.

17. Dreyer NA, Velentgas P, Westrich K, et al. The GRACE checklist for rating the quality of observational studies of comparative effectiveness: a tale of hope and caution. J Manag Care Spec Pharm 2014;20:301-8.

18. Cheng X. Comparison of Efficacy and Adverse Reactions of E. coli L-Asparaginase and Pegaspargase in Treatment of Children with Acute Lymphoblastic Leukemia. Evaluation and analysis of drug-use in hospitals of China 2015;15:1009-11.

19. The Cooperation Group of Phase II Clinical Trial of PEG-Asp. Comparison of polyethylene glycol conjugated asparaginase and E. coli L-Asparaginase for treatment of childhood acute lymphoblastic leukemia. Zhonghua Xue Ye Xue Za Zhi 2008;29:29-33.

20. Feng J. An efficacy observation of domestic pegaspargase in the treatment of children with initial acute lymphoblastic leukemia. China Medical Engineering 2015;23:86-7.

21. Jin Y. Adverse reactions of pegaspargase in the treatment of children with acute lymphoblastic leukemia and its prevention treatment. For All Health 2014;8:99-100.

22. Li F, Zhou P. Clinical comparison of permenthase and E. coli L-Asparaginase in the treatment of acute lymphoblastic leukemia in children. Chinese Journal of Convalescent Medicine 2019;28:1028-30.

23. Liu F, Zou Y, Zhang L, et al. Long-term efficacy of polyethylene glycol conjugated asparaginase (PEG-Asp) in newly diagnosed childhood acute lymphoblastic leukemia (ALL). Journal of China Pediatric Blood and Cancer 2010;15:254-7.

24. Liu Z. Clinical observation of pegaspargase in the treatment of children with acute lymphoblastic leukemia. Chinese Community Doctors 2019;35:51-2.

25. Shi L, Huang S, Liu W. Comparison of efficacy of pegaspargase and E. coli L-Asparaginase in the treatment of children with acute lymphoblastic leukemia. Clinical Research 2019;27:58-9.

26. Tang Y, He Z, Jin J, et al. Comparison of Efficacy of Pegaspargase and E. coli L-Asparaginase in the Treatment of Children with Leukemia. Laboratory Medicine and Clinic 2016;13:233-4.

27. Wu H. Curative effect comparison and safety evaluation of pegaspargase and E. coli L-Asparaginase in the treatment of children with acute lymphoblastic leukemia. Chinese Community Doctors 2016;32:38-9.

28. Xia L. The curative effects and safety of pegaspargaseasparaginase on acute lymphoblastic leukemia in children. Journal of North Sichuan Medical College 2016;31:644-7.

29. Xie S, Liang C, Zhong X. The side effects and clinical efficacy of pegaspargase and E. coli L-Asparaginase in the treatment of childhood acute lymphoblastic leukemia. National Medical Frontiers of China 2013;8:60-1.

30. Zhang H, Li H, Li Y. Observation on clinical effect of pegaspargase in treating acute lymphoblastic leukemia of childhood. Chinese Journal of Rational Drug Use 2018;15:16-9.

31. Zhang S. Clinical analysis of pegaspargase on early onset of acute lymphoblastic leukemia in children. Chinese Journal of Trauma and Disability Medicine 2015;(4):32-3.

32. Zhang S, Liu L, Yang Y, et al. Analysis of toxicity and efficacy of chemotherapy pegaspargase and E. coli L-Asparaginase acute lymphoblastic leukemia. Journal of Hunan Normal University (Medical Sciences) 2015;12:95-7.

33. Medawar CV, Mosegui GBG, Vianna CMM, et al. PEGasparaginase and native Escherichia coli L-asparaginase in acute lymphoblastic leukemia in children and adolescents: 
a systematic review. Hematol Transfus Cell Ther 2020;42:54-61.

34. Hasan H, Shaikh OM, Rassekh SR, et al. Comparison of hypersensitivity rates to intravenous and intramuscular

Cite this article as: Dai ZJ, Huang YQ, Lu Y. Efficacy and safety of PEG-asparaginase versus $E$. coli L-asparaginase in Chinese children with acute lymphoblastic leukemia: a metaanalysis. Transl Pediatr 2021;10(2):244-255. doi: 10.21037/tp-20178
PEG-asparaginase in children with acute lymphoblastic leukemia: A meta-analysis and systematic review. Pediatr Blood Cancer 2017;64:81-8. 


\section{Supplementary}

Table S1 Demographic and other baseline information of the children with CHD

\begin{tabular}{lccc}
\hline Indicator & $\mathrm{N}($ mean $\pm \mathrm{SD})$ & Normal blood coagulation & Abnormal blood coagulation \\
\hline Sex $(\mathrm{M} / \mathrm{F})$ & $1,690(941 / 749)$ & $497(50.35 \%) / 490(49.65 \%)$ & $444(63.16 \%) / 259(36.84 \%)$ \\
Age & $1,690(1.751 \pm 2.731)$ & $987(2.555 \pm 3.132)$ & $703(0.623 \pm 1.405)$ \\
PT & $471(11.221 \pm 0.664)$ & $415(11.110 \pm 0.658)$ & $56(11.202 \pm 0.709)$ \\
APTT & $471(34.655 \pm 2.805)$ & $415(34.692 \pm 2.790)$ & $56(34.382 \pm 2.927)$ \\
INR & $471(0.974 \pm 0.056)$ & $415(0.973 \pm 0.056)$ & $56(0.983 \pm 0.063)$ \\
FBG & $471(2.497 \pm 0.408)$ & $415(2.499 \pm 0.402)$ & $56(2.480 \pm 0.457)$ \\
WBC & $1,378(10.291 \pm 5.107)$ & $845(9.643 \pm 4.732)$ & $533(11.318 \pm 5.501)$ \\
PLT & $1,109(328.318 \pm 145.780)$ & $678(324.153 \pm 133.130)$ & $431(334.870 \pm 163.663)$ \\
HB & $745(120.728 \pm 27.941)$ & $478(119.839 \pm 22.941)$ & $267(122.318 \pm 35.154)$ \\
HCT & $745(36.771 \pm 7.886)$ & $478(36.424 \pm 6.345)$ & $267(37.394 \pm 10.058)$ \\
MCV & $1,378(82.990 \pm 8.884)$ & $845(81.277 \pm 8.063)$ & $533(85.708 \pm 9.439)$ \\
MCHC & $1,378(333.340 \pm 18.799)$ & $845(335.298 \pm 18.706)$ & $543(27.256 \pm 3.054)$ \\
MCH & $1,378(27.690 \pm 3.381)$ & $845.236 \pm 18.544)$ & $533(28.377 \pm 3.743)$
\end{tabular}

PT, prothrombin time; APTT, activated partial thromboplastin time; INR, international standardized ratio; FBG, fibrinogen; WBC, white blood cell count; PLT, platelet count; HB, hemoglobin; HCT, hematocrit; MCV, mean corpuscular volume; MCHC, mean corpuscular hemoglobin concentration; $\mathrm{MCH}$, mean corpuscular hemoglobin.

Table S2 Parameters of conventional coagulation tests and their reference range

\begin{tabular}{lccc}
\hline Parameter & Normal & Hypocoagulation & Hypercoagulation/hyperfibrinolysis \\
\hline PT (s)/INR & $9.4-12.5$ & $>12.5$ & $<9.4$ \\
INR & $0.8-1.2$ & $>1.2$ & $<0.8$ \\
APTT (s) & $25.1-38.4$ & $>38.4$ & $<25.1$ \\
Fib (g/L) & $2-4$ & $<2$ & $>4$ \\
D-dimer (mg/L) & $0-0.24$ & - & $>0.24$ \\
ATIII (\%) & $83-128$ & $>128$ & $<83$ \\
\hline
\end{tabular}

PT, prothrombin time; INR, international standardized ratio; APTT, activated partial thromboplastin time; ATIII, anticoagulant enzyme III. 